A - Research concept and design

B - Collection and/or assembly of data

$\mathrm{C}$ - Data analysis and interpretation

D - Writing the article

E - Critical revision of the article

F - Final approval of article

Received: 2020-07-15

Accepted: 2020-12-29

Published: 2021-01-03

\section{The influence of static stretching of specific lower limb muscle groups on the jump height parameter of volleyball players aged 16-17: a pilot study}

\author{
Agnieszka Beata Ćwirlej-Sozańska*1,A,C,E-F (D), Olaf Wójcik',A-D,F (D), \\ Jan Wójcik 2,A-D,F iD, Marzena Mól2,A-D,F iD, Tomasz Kolasa 2,A-D,F \\ ${ }^{1}$ Institute of Health Sciences, Medical College of Rzeszów University, \\ Poland \\ ${ }^{2}$ Scientific Club of Physiotherapy in Geriatrics and Health Prevention, \\ Section of Physioprophylaxis, Institute of Health Sciences, Medical College \\ of Rzeszów University, Poland
}

*Correspondence: Agnieszka Beata Ćwirlej-Sozańska; Institute of Health Sciences, Medical College of Rzeszów University, Poland; email: sozanska@ur.edu.pl

\begin{abstract}
Introduction: The jump is one of the most important parameters in volleyball. Often, warm-up exercise strategies are based on static stretching. The aim of the study is to show whether the static stretching of muscles of the lower limbs influences the jump parameter of volleyball players.

Materials and methods: The study included 25 players (16-17 years) from the club AKS Resovia Rzeszów. The study consisted of two measurements (M1 and M2) with intervention conducted between them. The vertical jump and heel to buttock tests were performed. Quadriceps femoris, iliopsoas and gastrocnemius were subjected to static stretching.

Results: Statistically significant differences in the heel-buttock test between the M1 and M2 for both right and left lower limbs were found. The average distance between the anthropometric points in M1 for the left lower limb was $14.54 \pm 6.16 \mathrm{~cm}$. This tendency was similar to the right lower limb. After the intervention in M2, the average distance was $11 \pm 6.06 \mathrm{~cm}$. A significant reduction of the value of the vertical jump after the intervention has been noted. The average value of the jump before the intervention was $325.64 \pm 10.15 \mathrm{~cm}$. In M2 the mean value was $324.24 \pm 9.81 \mathrm{~cm}$. The difference between M1 and M2 was statistically significant.

Conclusions: It has been found that in the study group static stretching had negative influence on the jump parameters directly after performing it. A positive effect of static stretching on increasing the range of mobility of the knee joint was noted.
\end{abstract}

Keywords: heel-buttock, static passive stretching, test vertical jump, volleyball

\section{Introduction}

Jump height is one of the most often sought-after parameters in numerous sport disciplines, such as volleyball for instance. In the case of volleyball players, jumps are an essential movement action during the game. The myotatic reflex is a crucial muscle work mechanism employed during the natural movement functions [1]. The effect of muscle work, which results in increased strength, power and speed of contraction, is greater if the stretch phase precedes the contraction phase [2]. Due to the fact that different stretching methods influence the physiological muscle parameters in different ways, the research results of the influence of stretching on muscle power is not definite [3]. 
The height of a stationary vertical jump with arm swings is either one of the elements indicating motor potential or is directly regarded as a measure of jumping ability [4]. Jumping ability is one of the most important strength-speed indicators in volleyball. It appears in many forms depending on the element of the game. It is correlated with the explosive muscle strength and despite the fact that side-jumping and jumping to attack are technically different elements, their physiological mechanisms are almost identical [5]. It has been proven that there is a distinct correlation between jump height results and the explosive strength of limb muscles. The increase of explosive strength of the lower limbs is accompanied by an increase in jump height [6].

Warming up is an essential element of training in any sport, because it accelerates the sportsperson's adaptation to exercise and reduces the risk of injury [7]. As a result of the research carried out by Maiiou, Obałkowska, Subasi et al., who performed it on a group of aerobics instructors, they have confirmed the positive influence of warm-up and stretching exercise on the motor system [8-10]. As such, introducing static stretching exercise into the warm-up phase has become the norm [11,12]. However, there is a question if this exercise is definitely beneficial?

In spite of the fact that static stretching improves muscle flexibility, its positive influence on jump height is doubtful [13]. Research results regarding the influence of stretching on the jump quality differ and do not present an answer to the question whether its introduction is justified. Reid et al. believe that static stretching has a positive influence, both on the increase of mobility range as well as the jump capabilities of the player [14]. Darymple et al. share this idea claiming that static stretching does not have any negative consequences as far as jump parameters are concerned [15]. According to Vuk et al., the time spent on stretching a given muscle group has a different influence on muscle efficiency. When the stretching lasts 60 seconds, a negative influence on muscle strength is observed [16,17], whereas stretching that lasts between 15 and 30 seconds has less or no negative effect on their strength [18]. Robbins et al. present the results of research, conducted among a group of men (training athletics and football players), which show a decrease or no improvement with reference to jump ability as a result of static stretching $[19,20]$. Moreover, Bishop shows that the positive effects of stretching last up to 5 minutes, after that time no positive influence on long-term activity is observed [21]. Morrin and Redding, who are between these two schools of opinion, claim that the best effects on improving mobility as well as jump ability can be achieved by combining static and dynamic stretching. According to the researchers, only such a combination of the two may bring a positive effect whereas choosing only one will always bring deficiency of movement or physical ability [22]. Furthermore, other research shows that taking part in a standard warm-up after static stretching, which would be a kind of pre-training prevention, may reduce its negative influence on generating muscle strength $[23,24]$. Based on analysis of the conducted research on the subject, Behm et al. note that the results are not definite and the difference in the movement range is between $+5 \%$ and $-20,5 \%$ [17]. They also suggest that the variety of results is a basis to continue the research in this field.

Due to the difference in research results concerning the influence of static stretching on the explosive strength of lower limbs, we have decided to carry out research on a group of volleyball players. The aim of the study is to show the influence of 60 second static stretching of Quadriceps femoris, Iliopsoas, Gastrocnemius and Soleus (knee joint extensor, hip joint flexors and foot plantar flexor) on the height of vertical jump and results of the heel-buttock test among 16-17 aged volleyball players.

\section{Materials and methods}

The research was conducted in "AKS Resovia Rzeszów" volleyball club after gaining approval to do so from the coach. The club counts 32 players. The following inclusion criteria has been designed in order to participate in the study: 16-17 years old, regularly taking part in training (at least 3 times a week) during the last 2 years, up to date medical examination and approval from a sport medicine physician, a health status enabling a safe intervention, voluntary informed consent of the player or a parent/legal guardian. The exclusion criteria included recent injuries of the musculoskeletal system, which would exclude the player from training, infections and severe inflammations which would cause a temporary lack of disposition of the player during the research.

In total, 25 boys aged 16-17 (Mean = 16.6; $\mathrm{SD}=0.5$ ), who were active in the preparation period of the yearly training cycle (2019/2020) took part in the research. The average weight of the players was $77,4 \mathrm{~kg}(\mathrm{SD}=7.72 \mathrm{~kg})$ and height was $190.3 \mathrm{~cm}$ $(\mathrm{SD}=5.87 \mathrm{~cm})$. The mean BMI was $21.4(\mathrm{SD}=1.68)$. 7 club players did not take part in the research $(3 \mathrm{did}$ not participate in training during the research, 2 did not give consent for taking part in the research, 2 had a recent injury) (Fig. 1). All of the participants trained regularly for an average of 16 hours per week for two years preceding the research. 


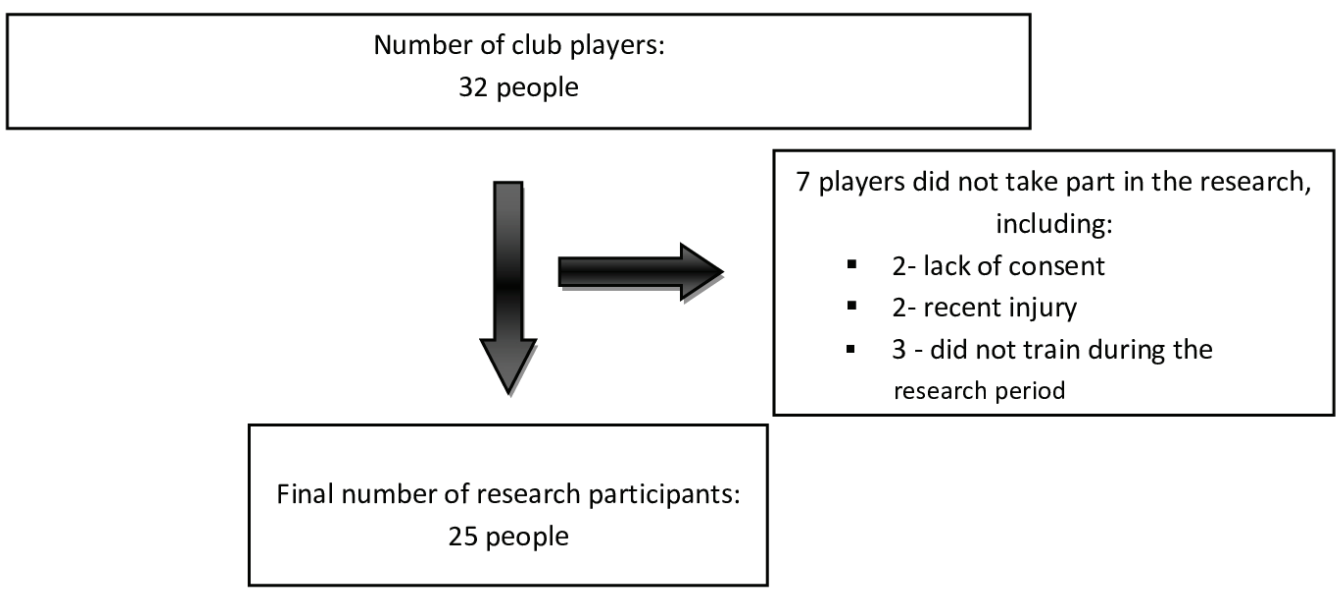

Fig. 1. Flow diagram of the study

The research was performed during one day in the afternoon among all players. It consisted of two measurements (M1 and M2) as well as an intervention conducted between them. Before starting the research, a standard warm-up was executed by the coach (in order to provide conditions close to normal), but without static stretching exercises at the end. The warm-up lasted for about 20 minutes and comprised running and development exercise typical for volleyball. There was no stretching exercise.

In order to conduct measurements (M1 and M2) the following tests were performed:

1) The heel-buttock test [25]

The purpose of this test was to evaluate the flexibility of the rectus femoris muscle. It was carried out in the prone position. The researcher kneeled on contralateral side to the tested limb. The researcher stabilized the participant's pelvis with the forearm. The player's foot was placed in the researcher's elbow fossa. The knee was actively flexed by the researcher until the soft tissue barrier was reached. The researcher used a centimeter measuring tape to measure the distance between the heel and the buttock. In order to increase the accuracy of the measurement, the researcher chose a specific point to place the tip of the tape - the crossing of the line running up the anterior superior iliac spine with the perpendicular line linking femur trochanters. The purpose of this test was to determine the influence of the stretching exercise on the tension of quadriceps muscles as well as the range of motion of the knee joint. Evaluation of the measurement was done twice by the same researcher in order to achieve the lowest possible subjective error. The results were recorded by the second researcher right after the evaluation. Better result (shorter distance between those two points) was analyzed. The first researcher did not have insight into the results to avoid manipulation [25].
2) Vertical jump [26]

This action is started from upright position. Right handed players start their run up with left leg, while left handed players with right. Spike attack consists of 3 step approach accompanied with arms swing. Next quick vertical jump is performed with dominant arm swinging backwards and then forwards during maximum jump height.

After the heel-buttock test, the players performed vertical jumps three times in one-minute intervals, by jumping to attack, which is characteristic for volleyball. The first jump was preparatory. Their jump height was measured by the use of a Vertec jump test device. While at the top point of the jump, the players touched bars determining the jump height. This allowed for the measurement of the reach of the player's upper limbs at the highest point. The reach was measured twice, each time after the heel-buttock test by the same researcher (overall six jumps were done). Each time a better result was analyzed [26].

The intervention was prepared based on the research of Galetin et al. [27], who also tried to determine the influence of stretching exercise on jump ability.

Intervention process:

1) Stretching the Quadriceps and Iliopsoas muscles (60 seconds for the left and right lower limb).

Implementation: Initial position - kneeling on one leg, back to the wall, trail leg bent at the knee, front part of the lower leg and dorsal part of the foot adjacent to the wall. Movements: pelvis retroflection, torso straight.

2) Stretching Gastrocnemius muscles (60 seconds, both sides).

Implementation: Initial position - standing position, the forefoot on the lowest bar of the ladder with the knee joints straightened. Movements: the heels moving towards the floor (until dorsal bend of the foot is reached). Maintaining the position for 60 seconds. 
3) Stretching Soleus muscles (60 seconds for the right and left lower limb).

Implementation: Initial position - kneeling on one leg, facing the wall, trail leg bent at the knee joint. The distance between the wall and toes of the trail leg should be equal to two fists of the player. Movements: deepening of the dorsal bend of the trail leg's foot by motioning the knee towards the wall without detaching the heel from the floor.

Additional information regarding each player's height and mass was gathered.

According to the Declaration of Helsinki, all participants were informed of the purpose and course of the research and they gave conscious consent to participate in the research. The research project was approved by the Bioethics Commission of the Rzeszów University (Decision no. 2019/05/31a).

\section{Statistical analysis}

The gathered data was analyzed with the use of Statistica Dell Inc. (2016) software. Dell Statistica (data analysis software system), version 13. Descriptive statistic measures were implemented for the initial data analysis. The t-Student test was used to compare results before and after the intervention for dependent samples. A statistical significance level of $p<0.05$ was used. In order to measure the normality, the Shapiro-Wilk test was used.

\section{Results}

Regarding the study group, the results of the heelbuttock test for the left lower limb ranged between 1 and 23 centimeters. The average distance between anthropometric points in the M1 measurement of the heel-buttock test for the left lower limb was $14.5 \pm 6.2 \mathrm{~cm}$. After intervention in the M2 measurement the minimum value remained the same, but the maximum value decreased by 3 centimeters. The average distance between anthropometric points in the heel-buttock test for the left lower limb was $11 \pm 6.1 \mathrm{~cm}$. The difference between M1 and M2 was statistically significant ( $<<0.0001)$ (Tab. 1).

This tendency was similar with the right lower limb. The results of the heel-buttock test for the right lower limb ranged between 1 and 25 centimeters. The average distance between anthropometric points during measurement M1 in the heel-buttock test for the right lower limb was $15.2 \pm 6.4 \mathrm{~cm}$. After intervention in the M2 measurement the minimum value remained the same, but the maximum value decreased by 7 centimeters. The average distance between the anthropometric points in the heel-buttock test for the right lower limb was $11.5 \pm 5.1 \mathrm{~cm}$. The difference between M1 and M2 was statistically significant ( $<<0.0001)$ (Tab. 1).

A significant lowering of the height of vertical jump after intervention was noted. The average jump value in the study group in the M1 vertical jump measurement

Tab. 1. The heel-buttock test - left/right lower limb

\begin{tabular}{|c|c|c|c|c|c|c|c|c|}
\hline $\begin{array}{l}\text { The heel-buttock test, } \\
\text { right/left lower limb }(\mathrm{cm})\end{array}$ & Average & Median & Min & $\operatorname{Max}$ & $\begin{array}{l}\text { Lower } \\
\text { quartile }\end{array}$ & $\begin{array}{l}\text { Upper } \\
\text { quartile }\end{array}$ & $\mathrm{SD}$ & $\mathrm{p}$ - value \\
\hline \multicolumn{9}{|l|}{ Left lower limb } \\
\hline before intervention & 14.5 & 16.5 & 1.00 & 23.0 & 13.0 & 18.0 & 6.2 & \multirow{2}{*}{$<0.0001^{1}$} \\
\hline after intervention & 11.0 & 13.0 & 1.00 & 20.0 & 9.0 & 15.0 & 6.1 & \\
\hline \multicolumn{9}{|l|}{ Right lower limb } \\
\hline before intervention & 15.2 & 15.0 & 1.00 & 25.0 & 13.0 & 20.0 & 6.4 & \multirow{2}{*}{$<0.0001^{1}$} \\
\hline after intervention & 11.5 & 13.0 & 1.00 & 18.0 & 9.0 & 15.0 & 5.1 & \\
\hline
\end{tabular}

${ }^{1}$ - T test for dependent samples, SD - standard deviation.

Tab. 2. The vertical jump measurement

\begin{tabular}{lcccccccc}
\hline $\begin{array}{l}\text { Vertical jump } \\
\text { measurement }(\mathrm{cm})\end{array}$ & Average & Median & Min & Max & Lower quartile & Upper quartile & SD & p - value \\
\hline before intervention & 325.6 & 326.0 & 301.0 & 342.0 & 319.0 & 332.0 & 10.2 & $0.0003^{1}$ \\
after intervention & 324.2 & 325.0 & 301.0 & 341.0 & 317.0 & 329.0 & 9.8 & \\
\hline
\end{tabular}

${ }^{1}$ - T test for dependent samples, SD - standard deviation. 


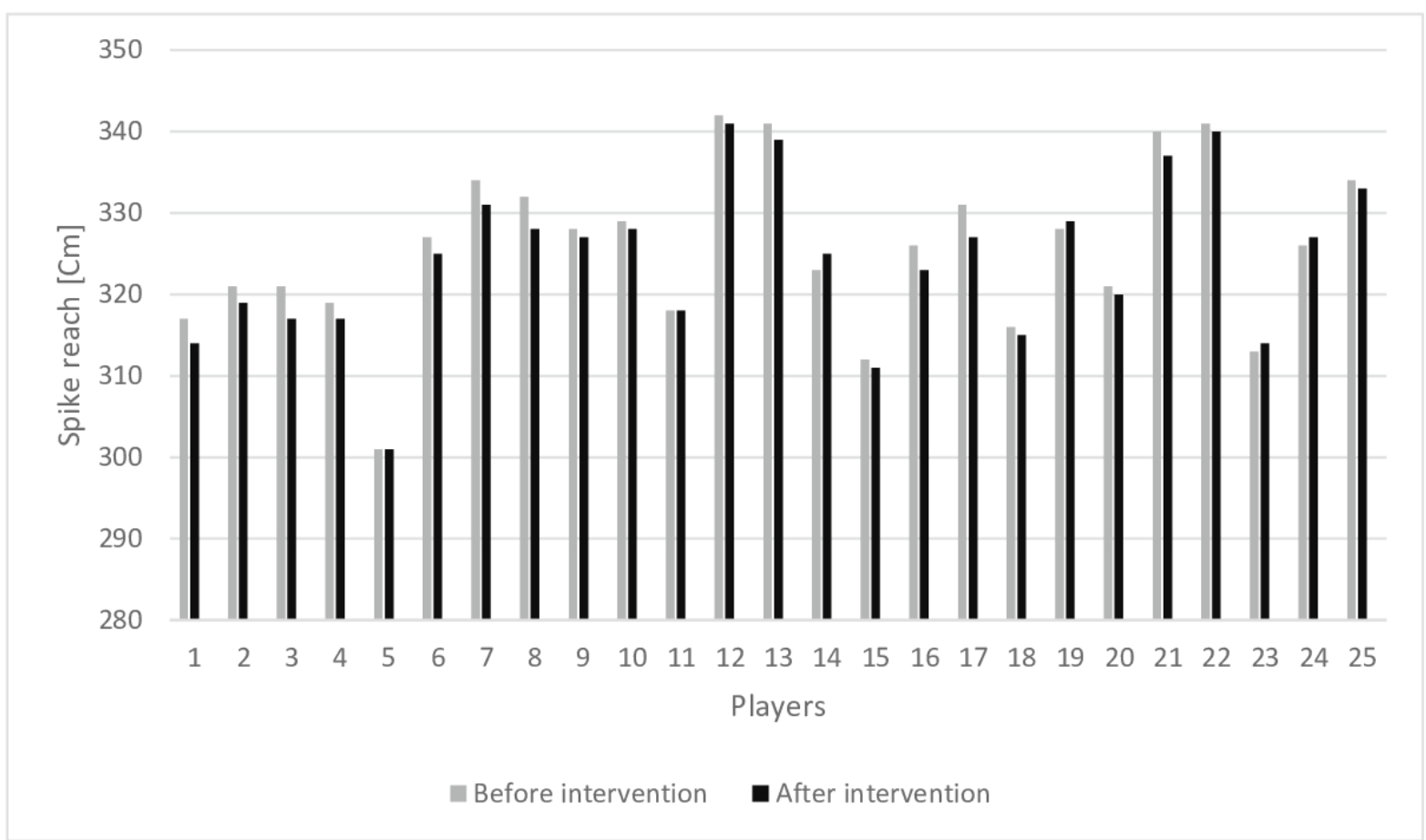

Fig. 2. The value of the height the vertical jump

was $325.6 \pm 10.2 \mathrm{~cm}$. After executing the intervention in measurement $\mathrm{M} 2$, the average vertical jump value was $324.2 \pm 9.8 \mathrm{~cm}$. The difference between M1 and M2 was statistically significant ( $p=0.0003)$ (Tab. 2).

What is more, Figure 2 also shows value of the height of the vertical jump for each of the players in the study group.

\section{Discussion}

The aim of this research was to evaluate the influence of static stretching of Quadriceps femoris, Iliopsoas, Gastrocnemius and Soleus on the height of the jump parameter, which subsequently corresponds to the attack or block range in volleyball.

The conducted research indicated that static stretching had a negative impact on the maximum height of the players' jump. Despite gaining a higher range of motion in the joints of the lower limbs, the participants presented worse jump parameters after the intervention. However, Jang et al. came to a different conclusion. Their results came from researching 16 badminton players, who executed different stretching types (static, dynamic, dynamic with resistance) after which the attack jump value was measured during the game. According to their findings, the choice of the method was not crucial as each of them had a positive influence on the vertical jump height. Their research showed that static stretching had improved this parameter by over $22 \%$ [28]. Lima et al., studied the influence of static and ballistic stretching on the jumping capabilities of ballet dancers. The study group performed 6 stretching exercise which concentrated on the quadriceps and popliteus muscles. Lima et al. proved that stretching does not have a negative impact on the jump parameter [29]. Moreover, Álvarez-Yates and García-García also obtained different results. Based on their research conducted among 16 rowers, they surmised that static stretching might have a positive influence as not only does it not disturb but improves the strength-speed parameters [30].

On the other hand, further researchers confirmed results recorded in our research. Silva et al. subjected muscles of the sole of the foot to bending among 17 young men. They performed one-legged jumps before and after intervention. Based on their results, the authors decided that static stretching resulted in a greater mobility rate in the hock joint from $21 \pm 4^{\circ}$ to $26.5 \pm 5^{\circ}$, but at the same time it worsened the jump parameters. The authors explained that this was a result of the increase in mobility rate, which decreased the peak muscle strength as well as the movement initiation capabilities [31]. Galetin et al. also confirmed the negative effect of static stretching on jump ability. When studying a group of 61 female volleyball players, they compared the effect of static stretching of the lower limbs performed for 30,60 or 90 seconds on the jump parameters. The "Probotics" 8602 Esslinger Court Huntsville Al 25802 was used to gather the data regarding jump abilities. The results indicated that regardless the length of time the static stretching was performed, jump parameters 
decreased. This dependence was statistically significant $(p=0.000)$. The authors also suggested, avoiding static stretching directly before dynamic activities as they led to a decrease of strength and speed [27]. Bogdanis et al. came to similar conclusions comparing the influence of interrupted and continuous static stretching on the jump parameters of 16 junior-high participants. They proved that constant static stretching led to an increase in knee joint mobility, which was analyzed using a modified Thomas test. Moreover, continuous static stretching led to a decrease of vertical jump. The jump was measured using the ErgoJump Bosocosystem platform [32]. Oliveira et al. also showed a dependency among 12 football players between stretching and jumping. An intervention was performed, which consisted of a 13 minute static stretching session. Next a mobility and jump measurement were made. The mobility measurement was made through a sit and stretch test. The researchers noticed that static stretching positively influenced the improvement of the mobility range whilst at the same time decreased jump parameters [33].

The limitation of the study is the performance of a test to assess the flexibility of a selected muscle group and the small group of subjects analyzed. The obtained results suggest that future research should introduce the evaluation of more biomechanical parameters to assess the effect of static stretching on the jump parameter, as well as evaluate it at various time intervals. The use of more sensitive measuring devices is also worth considering. A more detailed explanation of the influence of static stretching on the actual jump parameter is very important, because the warm-up of players usually ends with static stretching of the muscle groups of the lower limbs.

\section{Conclusions}

On the basis of the conducted research, it has been found that in the study group static stretching of Quadriceps femoris, Iliopsoas, Gastrocnemius and Soleus had negative influence on the jump parameters directly after performing it. However, it is worth noting, that static stretching helps increase the range of motion of the knee joint. Further research investigating the correlation between the mobility increase in the joint and the jump ability is recommended. Due to the discrepancy in the results of multiple researchers, it is advised to perform more studies focused on showing the significance of performing static stretching before physical exertion requiring effective elements of jumping.

\section{Funding}

This research received no external funding.

\section{Conflicts of interest}

The authors declare no conflict of interest.

\section{References}

1. George Z. Mentis, Fundamental Neuroscience, 4th ed. 2013, 613-30.

2. Bober T, Rutkowska-Kucharska A, Pietraszewski B. Ćwiczenia plyometryczne - charakterystyka biomechaniczna, wskaźniki, zastosowania. Sport wyczynowy. 2007; (7-9): 511-3.

3. Opplert J, Babault N. Acute Effects of Dynamic Stretching on Muscle Flexibility and Performance: An Analysis of the Current Literature. Sports Med. 2018 Feb; 48(2): 299-325.

4. Christensen BK, Nordstorm BJ. The Effects of Proprioceptive Neuromuscular Facilitation and Dynamic Stretching Techniques on Vertical Jump Performance J Strength Cond Res. 2008 Nov; 22(6): 1826-31.

5. Ruffieux J, Wälchli M, Kim KM, Taube W. Countermovement Jump Training Is More Effective Than Drop Jump Training in Enhancing Jump Height in Non-professional Female Volleyball Players. Front Physiol. 2020 Mar 17; 231(11): 1-6.

6. Elbadry N, Hamza A, Pietraszewski P, Alexe DI, Lupu G. Effect of the French Contrast Method on Explosive Strength and Kinematic Parameters of the Triple Jump Among Female College Athletes. J Hum Kinet. 2019; 69: 225-30.

7. Łubiński S, Kosendiak J. Rozgrzewka koszykarza - założenia teoretyczne, a rozwiązania praktyczne. Quality Sport. 2017; 3(3): 7-24.

8. Maiiou P, Rokka S, Beneka A, Mavridis G, Godolias G. Reducing risk of injury due to warm up and cool down in dance aerobic instructors. J Back Musculoskelet. 2007 May; 20(1): 29-35.

9. Obałkowska A. Naciąnięcia mięśni - mechanizmy urazu, zapobieganie. Fizjoterapia. 2003; 11(4): 37-50.

10. Subasi SS, Gelecek N, Aksakoglu G. Effects of different warm-up periods on knee proprioception and balance in healthy young individuals. J Sport Rehab. 2008; 17(2): 186-205.

11. Boguszewski D, Adamczyk JG, Ochal A, Wrzosek D, Białoszewski D. Wpływ rozgrzewki na ograniczenia funkcjonalne aparatu ruchu-badanie pilotażowe. Med Sport. 2017; 1(4)33:61-8.

12. Shier I. Warm-up and stretching in the prevention of muscular injury. Sports Med. 2008; 38(10): 879-80.

13. Paradisis GP, Pappas PT, Theodorou AS, Zacharogiannis EG, Skordilis EK, Smirniotou AS. Effects of static and dynamic stretching on sprint and jump performance in boys and girls. J Strength Cond Res. 2014; 28(1): 154-60. 
14. Reid JC, Greene R, Young JD, Hodgson D, Blazevich A, Behm DG. The effects of different durations of static stretching within a comprehensive warm-up on voluntary and evoked contractile properties. Eur J Appl Physiol. 2018; 118(7): 1427-45.

15. Darymple KJ, Davis SE, Dwyer GB, Moir GL. Effect of static and dynamic stretching on vertical jump performance in collegiate women volleyball players. J Strength Cond Res. 2010; 24(1): 149-55.

16. Stevanovic VB, Jelic MB, Milanovic SD, Filipovic SR, Mikic MJ, Stojanovic MDM. Sport-Specific Warm-Up Attenuates Static Stretching - Induced Negative Effects on Vertical Jump But Not Neuromuscular Excitability in Basketball Players. J Sports Sci Med. 2019; 18(2): 282-9.

17. Behm DG, Blazevich AJ, Kay AD, McHugh M. Acute effects of muscle stretching on physical performance, range of motion, and injury incidence in healthy active individuals: a systematic review. Appl Physiol Nutr Metab. 2016; 41(1): 1-11.

18. Simic L, Sarabon N, Markovic G. Does pre-exercise static stretching inhibit maximal muscular performance? A meta-analytical review. Scand J Med Sci Sports. 2013; 23(2): 131-48.

19. Robbins JW, Scheuermann BW. Varying amounts of acute static stretching and its effect on vertical jump performance. J Strength Cond Res. 2008; 22(3): 781-6.

20. Young W, Elliott S. Acute effects of static stretching, proprioceptive neuromuscular facilitation stretching, and maximum voluntary contractions on explosive force production and jumping performance. Res Q Exerc Sport. 2001; 72(3): 273-9.

21. Bishop D. Warm up I: potential mechanisms and the effects of passive warm up on exercise performance. Sports Med. 2003; 33(6): 439-54.

22. Morrin N, Redding E. Acute effects of warm-up stretch protocols on balance, vertical jump height, and range of motion in dancers. J Dance Med Sci. 2013; 17(1): 34-40.

23. Annino G, Ruscello B, Lebone P, Palazzo F, Lombardo M, Padua E, et al. Acute effects of static and dynamic stretching on jump performance after $15 \mathrm{~min}$ of reconditioning shooting phase in basketball players. J Sports Med Phys Fitness. 2017; 57(4): 330-7.

24. Samson M, Button DC, Chaouachi A, Behm DG. Effects of dynamic and static stretching within general and activity specific warm-up protocols. J Sports Sci Med. 2012; 11(2): 279-85.

25. Bidzińska G, Ptaszkowski K, Słupska L, Dymarek R, Zwierzchowski K, Kołcz-Trzęsicka A. et al. Evaluation of the Impact of Two Muscle Energy Techniques: Reciprocal Inhibition and Post-Isometric Muscle Relaxation on Bioelectrical Activity of Rectus Femoris Muscle - Randomised Preliminary Report. Piel Zdr Publ. 2015; 5(2): 131-9.

26. Leard JS, Cirillo MA, Katsnelson E, Kimiatek DA, Miller TW, Trebincevic K, et al. Validity of two alternative systems for measuring vertical jump height. J Strength Cond Res. 2007; 21(4): 1296-9.

27. Galetin N,Cvetković M, Ujsasi D, Čokorilo N, Andrašić S, Lazarević M. Effects of static stretching of various durations on the vertical jump among female volleyball players. FU Phys Ed Sport. 2017; 15(1): 207-17.

28. Jang HS, Kim D, Park J. Immediate effects of different types of stretching exercises on badminton jump smash. J Sports Med Phys Fitness. 2018; 58(7-8): 1014-20.

29. Lima CD, Brown LE, Ruas CV, Behm DG. Effects of Static Versus Ballistic Stretching on Hamstring: Quadriceps Strength Ratio and Jump Performance in Ballet Dancers and Resistance Trained Women. J Dance Med Sci. 2018; 22(3): 160-7.

30. Álvarez-Yates T, García-García O. Effect of a Hamstring Flexibility Program Performed Concurrently During an Elite Canoeist Competition Season. J Strength Cond Res. 2020; 34(3): 838-46.

31. Silva JJ, Behm DG, Gomes WA, Oliveira Silva FHD, Soares EG, Serpa ÉP, et al. Unilateral plantar flexors static-stretching effects on ipsilateral and contralateral jump measures. J Sports Sci Med. 2015; 14(2): 315-21.

32. Bogdanis GC, Donti O, Tsolakis C, Smilios I, Bishop DJ. Intermittent but Not Continuous Static Stretching Improves Subsequent Vertical Jump Performance in Flexibility-Trained Athletes. J Strength Cond Res. 2019; 33(1): 203-10.

33. Oliveira LP, Vieira LHP, Aquino R, Manechini JPV, Santiago PRP, Puggina EF. Acute Effects of Active, Ballistic, Passive, and Proprioceptive Neuromuscular Facilitation Stretching on Sprint and Vertical Jump Performance in Trained Young Soccer Players. J Strength Cond Res. 2018; 32(8): 2199-208. 